\title{
Creatinine based equations and glomerular filtration rate: interpretation and clinical relevance
}

\section{Introduction}

Chronic Kidney Disease (CKD) is now a major public health problem globally, more so in developing countries with Sub-Saharan Africa (SSA) being the most affected sub-region. ${ }^{1}$ A systematic review and metaanalysis estimated CKD prevalence in SSA to be $13.9 \% .^{2}$ In Ghana the true prevalence still remains unknown. The growing burden of CKD in Africa can be largely attributed to the rising prevalence of hypertension, diabetes and chronic glomerulonephritis. ${ }^{1,3}$ CKD affects people who are economically productive in the African continent ${ }^{1}$. Aside the heightened cardiovascular morbidity and mortality, CKD imposes huge economic burden on affected individuals and their care takers. ${ }^{1,3}$ Additionally patients with CKD suffer from various psychological problems such as depression, anxiety, cognitive dysfunction amongst others. ${ }^{4,5}$ Thus the disease, cost of treatment and these psychological problems may lead to poor quality of life. It is therefore imperative to make accurate diagnosis. The diagnosis of CKD is usually made by estimating Glomerular Filtration Rate (GFR). Measuring GFR is relatively cumbersome therefore more simple endogenous variables have been used to estimate renal function. The most commonly used variable is serum creatinine. ${ }^{6}$

\section{Serum Creatinine and Estimated GFR equations}

Creatinine based estimated equations used currently for diagnosing CKD include MDRD and CKD-EPI. The use of serum creatinine in estimating GFR is not without limitations. The most important limitation is the dependence of this biological marker on muscle mass. In view of this relationship to muscular mass, serum creatinine concentration and creatinine excretion vary with age, gender and ethnicity independent of changes in GFR. ${ }^{7,8}$ Thus several creatinine based equations have been developed taking into account age, gender and ethnicity amongst other variables to estimate GFR.,10 As a result serum creatinine level will differ for different ethnicities for the same level of GFR especially among Africans who typically have larger muscular mass than Caucasians and Asians. ${ }^{11,12}$ For the same GFR, serum creatinine levels are higher among Africans not because of high muscle mass per se but also because creatinine tubular secretion could be a variable according to ethnicity. ${ }^{7,13}$

Laboratory measurements of serum creatinine levels are subject to calibration bias. This is in reference to the differences in serum creatinine concentrations across \author{
bration.
}

various laboratories due to variations in the assay cali-

This is a very important matter in clinical application of estimated equations especially among people with normal serum creatinine levels. ${ }^{14,15}$ A bias of up to $0.37 \mathrm{mg} / \mathrm{dl}(32.7 \mu \mathrm{mol} / \mathrm{L})$ of serum creatinine measurement among laboratories in the United States has been reported. ${ }^{16}$ The clinical importance of this difference is shown by the fact that a serum creatinine level of $88 \mu \mathrm{mol} / \mathrm{L}$ in one laboratory may represent a value of $112 \mu \mathrm{mol} / \mathrm{L}$ in a different one. Applying this value to a 65-year-old African woman using CKD-EPI equation may give GFR ranging from 68.8 to 51.4 $\mathrm{mL} / \mathrm{min} / 1.73 \mathrm{~m}^{2}$, which obviously shows a possible decrease in kidney function. This may represent lack of standardization or calibration error among the laboratories. In order to generalize clinical applicability of creatinine based equations to all laboratories, reference materials must be standardized and traceable to a gold standard recognized institutions such as Ghana Standards Board, National Institute of Standards and Technology (NIST) amongst others.

Additionally estimated GFR equations cannot be uniform across the various clinical situations encountered by the physician globally. ${ }^{16}$ Evidence shows that the overall performance of MDRD estimated equation is superior to that of Cockcroft-Gault formula in estimating GFR, because the later estimates creatinine clearance and not GFR. ${ }^{9}$ More so, Cockcroft-Gault equation was developed among Caucasians and is thus inaccurate for estimating GFR among other ethnic groups. ${ }^{7,9,17}$

When the MDRD equation was introduced in 1999 a correction factor for African Americans was proposed. ${ }^{18}$ In recent times Chronic Kidney Disease Epidemiology Collaboration (CKD-EPI) equation was published with other ethnic factors. ${ }^{18,19}$ While MDRD equation was developed in people with GFR $<60 \mathrm{ml} / \mathrm{min} / 1.73 \mathrm{~m}^{2}$, the CKD-EPI was developed taking into consideration those with GFR of $>60 \mathrm{ml} / \mathrm{min} / 1.73 \mathrm{~m}^{2} \cdot{ }^{18,19}$ Recognition of the limitations of these equations is necessary when using the information obtained from them. More so the estimated equation will be clinically relevant in the settings that resemble the population and methods used to develop the equation. 
CKD is defined as a progressive loss of kidney function that last for more than three months to years and its classification depends largely on the degree of kidney damage; thus decline in GFR or presence of proteinuria. $^{20}$

Most patients usually visit our consulting rooms already psychologically disturbed because of laboratory results showing their estimated GFRs; it is therefore very important for clinicians to interpret laboratory results with estimated GFR in the context of the patient's clinical situation and not in isolation. Additionally a study by Eastwood et al, assessing GFR among Ghanaians in the Ashanti region using four methods, showed that CKDEPI appeared to be the most useful. ${ }^{12}$

\section{Conclusion}

Estimation of GFR to assess kidney function is appropriate for detection, evaluation and management of Kidney disease, nevertheless these equations should be interpreted in the context of the clinical setting in which it is applied. In addition, acknowledgement and recognition of the limitations of these estimated equations is important. Finally these equations may be more accurately applied in the settings that resemble the original population and methods used to develop the model such as patients with established chronic kidney disease for instance.

\section{Dr Vincent Boima MB, ChB, FWACP, Cert Nephrology (SA)}

Lecturer, Department of Medicine, University of Ghana School of Medicine and Dentistry, PO Box 4236, Accra

E-mail: vincentboima@yahoo.com

Conflict of interest: None declared

\section{REFERENCES}

1. Naicker S. End-stage renal disease in Sub-Saharan Africa. Ethn Dis Spring. 2009; 19(1 Suppl 1): S113

2. Stanifer JW, Jing B, Tolan S, et al. The epidemiology of chronic kidney disease in sub-Saharan Africa: a systematic review and meta-analysis. The Lancet Global Health;2:e174-e81.

3. Rashad S, Basroum MD. Chronic kidney disease in the developing world. N Engl J Med 2006 March; 354(10): 997-999

4. Cohen LM, Levy NB, Tessier EG, Germain, MJ. Renal Disease. In: Levenson JL, ed. The American Psychiatric Publishing textbook of psychosomatic medicine. 1st Ed. Washington: American Psychiatric Publishing; 2005 p.483-90

5. Finkelstein FO, Finkelstein SH. Depression in chronic dialysis patients: assessment and treatment. Nephrol Dial Transplant 2000;15:1911-3

6. Rehberg PB: Studies on kidney function: The rate of filtration and reabsorption in the human kidney. Biochem J 1926;20: 447-460

7. Goldwasser P, Aboul-Magd A, Maru M: Race and creatinine excretion in chronic renal insufficiency. Am J Kidney Dis 1997;30: 16-22

8. Jacobs DR Jr., Murtaugh MA, Steffes M, Yu X, Roseman J, Goetz FC: Gender- and race-specific determination of albumin excretion rate using albumin-to-creatinine ratio in single, untimed urine specimens: The Coronary Artery Risk Development in Young Adults Study. Am J Epidemiol 2002;155: 1114-1119

9. Cockcroft DW, Gault MH: Prediction of creatinine clearance from serum creatinine. Nephron 1976;16: 31-41,

10. Levey AS, Bosch JP, Lewis JB, Greene T, Rogers $\mathrm{N}$, Roth D: A more accurate method to estimate glomerular filtration rate from serum creatinine: A new prediction equation. Modification of Diet in Renal Disease Study Group. Ann Intern Med 1999;130: 461-470

11. Kramer H, Palmas W, Kestenbaum B, Cushman M, Allison M, Astor B, Shlipak M: Chronic kidney disease prevalence estimates among racial/ethnic groups: The Multi-Ethnic Study of Atherosclerosis. Clin J Am Soc Nephrol 2008;3: 1391-1397,.

12. Eastwood JB, Kerry SM, Plange-Rhule J, Micah FB, Antwi S, Boa FG, Banerjee D, Cappuccio FP: Assessment of GFR by four methods in adults in Ashanti, Ghana: The need for an eGFR equation for lean African populations. Nephrol Dial Transplant 2010;25: 2178-2187

13. Hsu CY, Chertow GM, Curhan GC: Methodological issues in studying the epidemiology of mild to moderate chronic renal insufficiency. Kidney Int 2002; 61: 1567-1576

14. Stevens LA, Coresh J, Greene T, Levey AS. Assessing kidney function-measured and estimated glomerular filtration rate. $N$ Engl J Med 2006, 354: 2473-2483

15. Poggio ED, Hall PM. Estimation of glomerular filtration rate by creatinine-based formulas: Any room for improvement? NephSAP 2006;5: 131-140

16. Martin E. Lascano, Emilio D. PoggioKidney Function Assessment by Creatinine-Based Estimation Equations. Cleveland Clinic for Continous Medical Education. Published: August 2010.

17. Lewis J, Agodoa L, Cheek D, Greene T, Middleton J, O'Connor D, Ojo A, Phillips R, Sika M, Wright J 
Jr.: Comparison of cross-sectional renal function measurements in African Americans with hypertensive nephrosclerosis and of primary formulas to estimate glomerular filtration rate. Am J Kidney Dis 2001;38: 744-753

18. Levey AS, Stevens LA, Schmid CH, Zhang YL, Castro AF III., Feldman HI, Kusek JW, Eggers P, Van Lente F, Greene T, Coresh J: A new equation to estimate glomerular filtration rate. Ann Intern Med 2009;150: 604-612
19. Stevens LA, Claybon MA, Schmid CH, Chen J, Horio M, Imai E, Nelson RG, Van Deventer M, Wang HY, Zuo L, Zhang YL, Levey AS: Evaluation of the Chronic Kidney Disease Epidemiology Collaboration equation for estimating the glomerular filtration rate in multiple ethnicities. Kidney Int 2011;79: 555-562

20. KDOQI Clinical Practice Guidelines for Chronic Kidney Disease: Evaluation, Classification, and Stratification. (C) 2002 National Kidney Foundation, Inc. $\boldsymbol{\theta}$ 